\title{
Research Paper: The Relationship Between Maximum Jump Performance and Force-time Variables of Block Landing Skill in Junior Elite Volleyball Players
}

\author{
Ali Fatahi ${ }^{* *}$ (D), Razieh Yousefian Molla ${ }^{1}$ (D) Mitra Ameli $^{2}$ (D) \\ 1. Department of Sports Biomechanics, Faculty of Physical Education and Sports Science, Central Tehran Branch, Islamic Azad University, Tehran, Iran. \\ 2. Department of of Physical Education and Sports Science, Faculty of Physical Education and Sports Science, Payame-E-Noor University, Karaj, Iran.
}

\begin{tabular}{|c|c|}
\hline $\begin{array}{l}\text { Use your device to scan } \\
\text { and read the article online }\end{array}$ & Crtation Fatahi A, Yousefian Molla R, Ameli M. The Relationship Between Maximum Jump Performance and Force-time \\
\hline 口:15 & $\begin{array}{l}\text { Variables of Block Landing Skill in Junior Elite Volleyball Players. Physical Treatments. 2021; 11(3):171-180. http://dx.doi. } \\
\text { org/10.32598/ptj.11.3.416.2 }\end{array}$ \\
\hline atitis & doi http://dx.doi.org/10.32598/ptj.11.3.416.2 \\
\hline
\end{tabular}

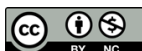

Article info:

Received: 26 Jun 2020

Accepted: 14 Feb 2020

Available Online: 01 Jul 2021

Keywords:

Jumping, Kinetic,

Volleyball, Landing,

Biomechanics

\begin{abstract}
A B S T RA C T
Purpose: Frequent and powerful jumps and landings in volleyball exert significant stresses on lower extremities which can be determinant of injury prevalence. This study aimed to investigate the possible correlation between Maximum Jump (MJ) performance and force-time variables of volleyball block landing.
\end{abstract}

Methods: Thirty elite junior volleyball players (Mean \pm SD of age: $18.140 \pm 1.125 \mathrm{y}$, sports background: $4.390 \pm 0.957 \mathrm{y}$, and height: $197.100 \pm 3.161 \mathrm{~cm}$ ) performed three block jumps, and best of trials was considered for further analysis. The study data were collected by the KISTLER force platform $(1000 \mathrm{~Hz})$. Force-time, velocity-time, and displacement-time were obtained using the Excel program. The Kolmogorov-Smirnov and Pearson correlation coefficient were used for assessing data normality and possible correlations between variables using SPSS v. $21(\mathrm{P}<0.05)$

Results: Peak vertical impact forces were reported in a range of 1.8-3.5 BW $\left(\mathrm{F}_{1}, \mathrm{~F}_{2}\right)$ during 27 to $83 \mathrm{~ms}$ of peak times $\left(\mathrm{T}_{1}, \mathrm{~T}_{2}\right)$. Significant positive correlations were obtained between temporal variables of time of peaks $\left(T_{1}, T_{2}\right)$, the time elapsed between peaks $\left(T_{p}\right)$, and end of landing time $\left(T_{f}\right)$. A significant negative correlation was found between $F_{2}$ and $T_{2}$ and a significant positive correlation between $\mathrm{MJ}$ performance with peak vertical forces $\left(\mathrm{F}_{1}, \mathrm{~F}_{2}\right)$.

Conclusion: According to the findings, T1 has little impact on shock absorption. Coaches and volleyball players should consider the importance of soft landing through increasing $\mathrm{T}_{2}$, which decreases $\mathrm{F}_{2}$, not only for performance improvement but also for reducing injuries.

\footnotetext{
* Corresponding Author:

Ali Fatahi, PhD.

Address: Department of Sports Biomechanics, Faculty of Physical Education and Sports Science, Central Tehran Branch, Islamic Azad University, Tehran, Iran. Phone: +98 (912) 25607581

E-mail:fattahiali81@gmail.com
} 


\section{Highlights}

- Importance of appropriate technique in landing;

- Optimum shock absorption through optimum timing of landing;

- Concerning the kinetics as an outstanding parameters in biomechanics of landing.

\section{Plain Language Summary}

Volleyball is considered as a sport with high frequency of jumping and landing. Volleyball players are susceptible to lower limbs injuries such as ankle sprain due to the nature of this sport. According to the previous researches biomechanics of landing play an outstanding role in injury prevention. Correlation between kinetic and temporal variables of landing has attracted experts of biomechancis. In this viewpoint it has been proposed that increasing the time between peaks of landing forces may lead to shock absorption. On the other hand, the aim of the players in volleyball is to reach the maximum height over the net. Here the question arises that whether correlation correlation exists between jumping height and kinetic- temporal variables of the jumping and landing performance in volleyball players. Results of the study revealed that significant correlations are obvious between maximum jumping height and peak forces as well as time between the peaks. Significant correlations between MJ height and temporal and kinetics variables of landing suggest that optimum timing in landing would lead to optimum shock absorption. As volleyball players are good jumpers, great stress would be placed on their lower extremities when landing. Increasing the time of the second peak $\left(\mathrm{T}_{2}\right)$ will decrease impact force $\left(\mathrm{F}_{2}\right)$, although it is not appropriate for volleyball goals.

\section{Introduction}

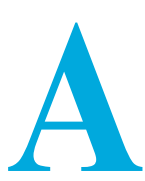

lthough volleyball is a non-contact game, forceful and repetitive movements make it a serious competitive sport with a relatively high musculoskeletal injury rate $[1,2]$. About $63 \%$ of total injuries are reported at jumping-landing maneuver, as a fundamental part of blocking and spiking skills [3]. Although some researchers believe in positive effects of jump and landing, such as optimal skeletal health $[4,5]$, large ground reaction force (GRF) during landing will make the lower extremity susceptible to injuries at the knee and ankle joints [1, 6-8]. In volleyball, jumping and landing are often performed, so volleyball players are at significant risk of high GRF [9]. Approximately 60 maximal jumping and landing per hour is reported for a volleyball match [10]. The resultant GRF is an order between 1 to 5 times of body weight (BW). It is more noticeable for front row players who perform many block jumps following landing during the game and practice [11]. The combination of high GRF, rapid loading times, and frequent jumping and landing during practice sessions and games are thought to be significant determinants of injury prevalence in volleyball players [12].
Researchers have investigated various landing techniques $[11,13]$. Common landing techniques which volleyball players use after block technique is called "non-flat foot" or "toe-heel pattern" [14], first with forefoot following by rearfoot contact to the ground. The main advantage of this landing is the remarkable smaller vertical GRF compared to the other techniques [12, 13, 15]. Biomechanically, this common type of landing is characterized by the first peak $\left(\mathrm{F}_{1}\right)$ and second peak $\left(\mathrm{F}_{2}\right)$ in the vertical ground reaction force (VGRF) curve with respect to time. $F_{1}$ is the result of forefoot impact and is estimated to produce 1 to $2 \mathrm{BW}$ at the moment of touchdown, while $\mathrm{F}_{2}$ is the impact of heel contact, producing 1 to $7 \mathrm{BW}$ for male volleyball players performing block skill [11]. However, sometimes a third smaller peak is evident in this curve that results from ankle flexion [15]. It is reported that $F_{2}$ is mainly responsible for landing-related injuries, but the underlying mechanism is still unknown $[14,15]$. The landing quality is explained by concentrating on the relationship between the amplitude and timing of these two peaks. Two high peak forces characterize a hard landing in a short period, and a soft landing is described by smaller peak forces during a more extended period. Performing frequent jumping and landing would produce significant loads on the lower extremity's joints and a predictor of injury incidence $[12,16-18]$. 
Some researchers have described biomechanical factors that can minimize the adverse effects of landing, such as kinematic parameters [9, 12, 19-21]. They suggest that impact forces and joints loading are reduced by increasing the landing time between two peaks through flexing lower extremity joints in an appropriate sequence. However, it might not be beneficial for volleyball goals. As in volleyball, many repetitive movements will occur very fast, and increasing the landing time will decrease the efficiency of the players in the game. Thus, biomechanical analysis of landing techniques has received significant attention to determine solutions for decreasing injuries and promoting performance simultaneously $[14,22]$. Biomechanical analysis of landing will prepare bases for modifications and alternations of risk factors that have the greatest potential for reducing injury prevalence, and many research studies have been conducted to investigate joint kinematics and GRF [18, 23, 24].

As mentioned earlier, landing is a technique with a high risk of injuries. In volleyball, most points are achieved through jumping-landing skills, so attention should be paid to appropriate execution and accurate biomechanical analysis of this technique. Indeed, jumping technique quality undeniably affects landing characteristics, and higher jumps have more kinetic effects on landing quality. Previous studies have mainly reported the importance of considering landing as a highrisk technique with respect to injury occurrence, but no scientific evidence is available concerning the kinetic and temporal analysis of landing techniques to monitor potential relationships among them. There is little knowledge about the biomechanical analysis of landing and its relationships among jump height performance, force, and temporal variables in block jumping and landing technique in volleyball. This study investigates the possible correlation between Maximum Jump (MJ) height and VGRF-time curve variables in the landing phase of block jump (Figure 1). The findings of this study can be helpful for volleyball players and coaches modify landing from a block jump concerning performance optimization and injury prevention.

\section{Materials and Methods}

\section{Study subjects}

The study was conducted at the Biomechanics Laboratory of the National Olympic Committee of Iran. Thirty healthy junior volleyball players of the national team participated in the study (Table 1). All players performed two training sessions for 4 hours every day. Subjects were excluded from the study if they had any musculoskeletal or neurological deficits or injury histories such as leg discrepancy, anterior cruciate ligament rupture, bone fracture, patellar dislocation, and meniscus tear that could influence landing biomechanics. The procedure was described for each subject clearly, and all participants signed the consent forms according to Helsinki Deceleration before data collection. The testing procedure was approved by the Ethics Committee of Islamic Azad University. All players were right-footed and right-handed.

\section{Study design}

The athletic task tested in this study was block landing. Block technique is a vertical jump performed with the contribution of the stretch-shortening cycle. The

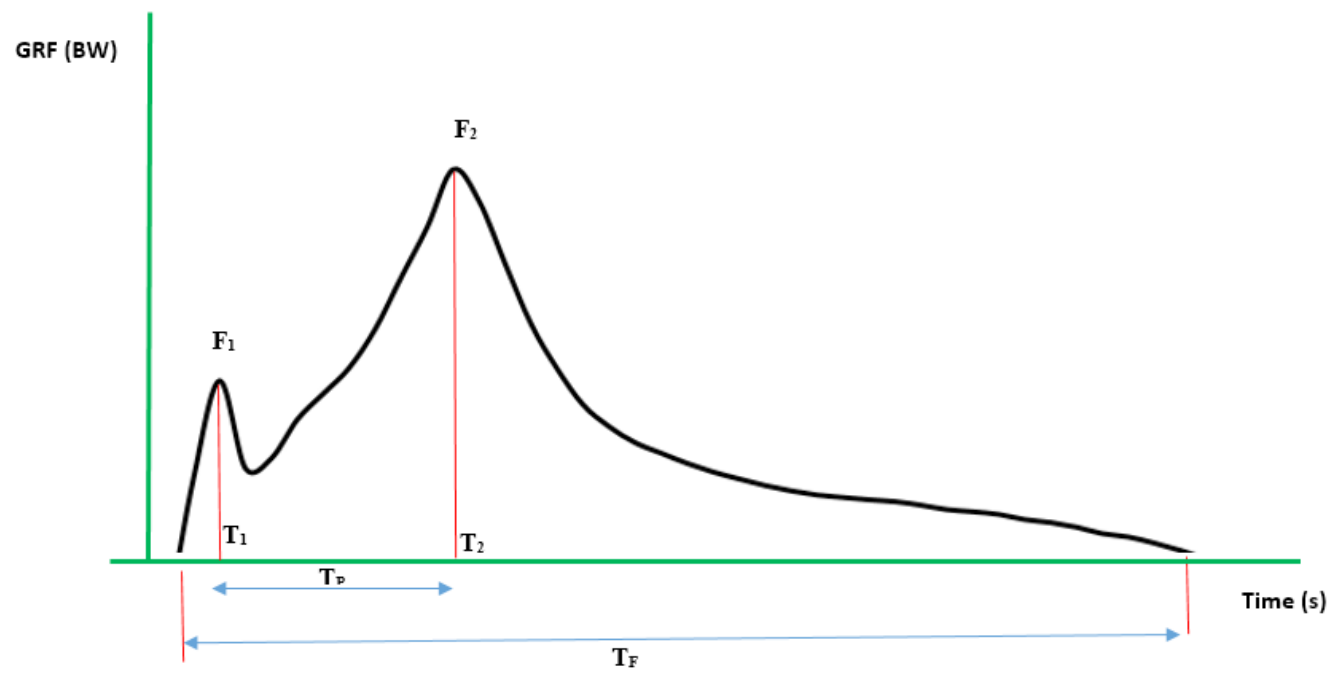

Figure 1. Force-time graph obtained from force plate during the landing phase of the block jump 
Table 1. Mean $\pm S D$ variables of junior elite volleyball players $(n=30)$

\begin{tabular}{cc}
\hline Variables & Mean \pm SD \\
\hline Age $(\mathrm{y})$ & $18.140 \pm 1.125$ \\
Height $(\mathrm{cm})$ & $197.100 \pm 3.161$ \\
\hline Sports background $(\mathrm{y})$ & $4.390 \pm 0.957$ \\
Weight $(\mathrm{N})$ & $771.200 \pm 59.835$ \\
\hline & PHYSICAL TREA $\$$ MENTS
\end{tabular}

subject starts from the ready position with the hands in front of his chest and fingers extended. Block jump begins with a preliminary downward movement by flexing at the knees and hips (eccentric phase), and then the knees and hips immediately extended again to jump vertically (concentric phase) while the hands moving upward and extended above the head. It is well accepted to have a minimum stop between the eccentric and the concentric phases to take advantage of the energy stored by the elastic elements of the muscles.

In the beginning, a warm-up protocol was performed individually for 15 minutes according to the official condition of the game. Each subject was allowed to practice three to five times to be more familiar with the appropriate procedure of the test. For minimizing the coach role, no verbal instructions were described for players.

\section{Data collection}

Data collection started with the calibration of the force platform system $\left(\right.$ Kistler $^{\circledR}$ force platform with a sampling rate of $1000 \mathrm{~Hz}$ ). The participants were asked to perform three maximal block jumps, and between each trial, have three minutes of rest. The vertical GRF was obtained directly from force plate system output. The vertical force acting on the Center of Mass (COM) was obtained by VGRF minus the participant's weight. Vertical force of COM divided by mass presents vertical acceleration, and by integrating acceleration with respect to time, the velocity is obtained. Double integrating acceleration concerning time showed displacement of COM, and maximum displacement of COM is obtained. All integration was performed by Microsoft Excel $^{\circledR} 2010$ by the Trapezoid rule. The Excel program calculates force-time, velocity-time, and displacementtime. Through these curves, peak vertical forces $\left(\mathrm{F}_{1}\right.$, $\mathrm{F}_{2}$ ) normalized to $\mathrm{BW}$, time of peaks $\left(\mathrm{T}_{1}, \mathrm{~T}_{2}\right)$, the time elapsed between peaks $\left(\mathrm{T}_{\mathrm{p}}\right)$, MJ as the differences between maximal COM position and standing upright position (MJ), and end of landing when the velocity of COM is zero $\left(\mathrm{T}_{\mathrm{f}}\right)$ are calculated. The ratios between peaks $\left(\mathrm{F}_{2} / \mathrm{F}_{1}\right)$ and between the peaks $\left(\mathrm{T}_{1} / \mathrm{T}_{\mathrm{f}}\right.$ and $\left.\mathrm{T}_{2} / \mathrm{T}_{\mathrm{f}}\right)$ are also calculated.

\section{Statistical analysis}

Statistical analysis was undertaken using SPSS v. 21. The indices of Mean \pm SD were used for descriptive analysis. The Kolmogorov-Smirnov (KS) test was used to examine the normality of data. If the data were found normally distributed, the Pearson correlation coefficient was performed to understand any possible relationship between the variables. All analyses were considered significant at $\mathrm{P}<0.05$.

\section{Results}

Table 2 presents the variables derived from analysis of block landing, including temporal and kinetic ones. Mean $\pm \mathrm{SD}$ values of $\mathrm{F}_{1}, \mathrm{~F}_{2}, \mathrm{~T}_{1}$, and $\mathrm{T}_{2}$ were $1.801 \pm 0.49$ (BW), $3.439 \pm 0.835$ (BW), $0.027 \pm 0.016 \quad(\mathrm{~s})$ and $0.083 \pm 0.034$ (s), respectively. Table 3 presents the Pearson correlation coefficient between variables. There are significant positive correlations between $T_{1}$ and $\mathrm{T}_{2}(\mathrm{r}=0.793, \mathrm{P}<0.01), \mathrm{T}_{1}$ and $\mathrm{T}_{\mathrm{p}}(\mathrm{r}=0.453, \mathrm{P}<0.05), \mathrm{T}_{2}$ and $\mathrm{T}_{\mathrm{p}}(\mathrm{r}=0.902, \mathrm{P}<0.01), \mathrm{T}_{2}$ and $\mathrm{T}_{\mathrm{f}}(\mathrm{r}=0.583, \mathrm{P}<0.05)$, $\mathrm{T}_{\mathrm{p}}$ and $\mathrm{T}_{\mathrm{f}}(\mathrm{r}=0.540, \mathrm{P}<0.05), \mathrm{T}_{1} / \mathrm{T}_{\mathrm{f}}$ and $\mathrm{T}_{2} / \mathrm{T}_{\mathrm{f}}(\mathrm{r}=0.833$, $\mathrm{P}<0.01)$ as well as negative correlation between $\mathrm{T}_{\mathrm{f}}$ and $\mathrm{T}_{2} / \mathrm{T}_{\mathrm{f}}(\mathrm{r}=-0.464, \mathrm{P}<0.05)$. There are positive and negative correlations between $\mathrm{F}_{1}$ and $\mathrm{F}_{2}(\mathrm{r}=0.532, \mathrm{P}<0.05)$ and between $\mathrm{F}_{1}$ and $\mathrm{F}_{2} / \mathrm{F}_{1}(\mathrm{r}=-0.645, \mathrm{P}<0.01)$, respectively. There are significant negative correlations between $\mathrm{T}_{2}$ and $\mathrm{F}_{2}(\mathrm{r}=-0.629, \mathrm{P}<0.01), \mathrm{T}_{\mathrm{p}}$ and $\mathrm{F}_{2}(\mathrm{r}=$ $0.612, \mathrm{P}<0.01), \mathrm{T}_{1}$ and $\mathrm{F}_{2} / \mathrm{F}_{1}(\mathrm{r}=-0.577, \mathrm{P}<0.01), \mathrm{F}_{2}$ and $\mathrm{T}_{2} / \mathrm{T}_{\mathrm{f}}(\mathrm{r}=-0.472, \mathrm{P}<0.05)$ and $\mathrm{F}_{2} / \mathrm{F}_{1}$ and $\mathrm{T}_{1} / \mathrm{T}_{\mathrm{f}}(\mathrm{r}=-0.492$, $\mathrm{P}<0.05)$. We also investigated the Pearson correlation coefficient between $\mathrm{MJ}$ and other temporal and kinetics variables and significant positive correlations were found between $\mathrm{MJ}$ and $\mathrm{F}_{1}(\mathrm{r}=0.752, \mathrm{P}<0.01)$, MJ and $\mathrm{F}_{2}$ $(\mathrm{r}=0.565, \mathrm{P}<0.01)$ as well as significant negative correlation between $\mathrm{MJ}$ and $\mathrm{T}_{\mathrm{p}}(\mathrm{r}=-0.459, \mathrm{P}<0.01)$. 


\section{Discussion}

This study aimed to investigate the possible relationship between jump height and selected kinetic and temporal variables of block landing. Values of impact forces $\left(\mathrm{F}_{1}\right.$ and $\left.\mathrm{F}_{2}\right)$ in our study were 1.8 to $3.5 \mathrm{BW}$, while $\mathrm{F}_{2}$ was two times greater than $\mathrm{F}_{1}\left(\mathrm{~F}_{2} / \mathrm{F}_{1}\right)$. This result agrees with some studies on volleyball spike and blocking jump [6, 7, 9, 11, 18, 25-31]. Hughes et al. reported 2 to $3 \mathrm{BW}$ impact forces for volleyball players with respect to gender [27]. Controversially, some other investigations reported higher values for $F_{1}$ and $F_{2}$ [15, 32-34]. Ortega et al. showed that landing impact forces would be between 2.5 and $10 \mathrm{BW}$ [15]. Abian et al. reported even more values up to $7.5 \mathrm{BW}$ [34].

Our subjects were elite junior volleyball players, while subjects in other studies were chosen from other populations such as football or even recreational sports. Because of the jumping and landing nature of volleyball, our study participants were familiar with the protocol of landing and block as critical skills in volleyball. So compared to the participants of the other studies, they can perform this technique more comfortably, including the landing phase. Besides, we should consider the kinematics of the lower extremity during landing. Knee and ankle flexion angles are considered a vital element in shock absorption. Landing with the knee flexed between $0^{\circ}$ and $25^{\circ}$ causes the greatest value of ground reaction, and increasing knee flexion leads to decreasing impact forces. Professional volleyball players know that this effect decreases landing force and possible injuries $[7,35]$. Some studies have dropped subjects from a fixed height to determine GRF, but in our study, the players were supposed to land from their blocking height, which is various for them.

The total time of landing, from the initial contact up to when the COM velocity would be zero, lasted $277 \mathrm{~ms}$ $( \pm 96)$. This period is longer than the results presented by some other authors $[15,36]$. Ortega et al. concluded that this time lasted only $144 \mathrm{~ms}$ [15], and Lee reported values between 150-200 ms [36]. The Mean \pm SD time of the first peak $\left(\mathrm{T}_{1}\right)$ and the second peak $\left(\mathrm{T}_{2}\right)$ are obtained $27 \pm 16 \mathrm{~ms}$ and $83 \pm 34 \mathrm{~ms}$, respectively. $\mathrm{T}_{1}$ appears at $10 \%$ and $\mathrm{T}_{2}$ at $31 \%$ of total landing time, approximately. These times are higher than reported by Abian et al. (2008), which were 10 and $45 \mathrm{~ms}$ [34]. The appearance of $\mathrm{T}_{1}$ and $\mathrm{T}_{2}$ have a significant role in impact absorption and is known as a vital factor for injury prediction. Temporal variables of landing are dependent on the foot length and eccentric contraction of plantar flexor muscles [34]. The COM path during landing is also another critical parameter. Perhaps, differences between foot length and activation pattern of mentioned muscle groups and displacement of COM in stabilizing and controlling the body are the reasons for disagreements.

Significant correlations were observed between temporal variables. There are noticeable controversies between our results and Ortega et al. (2010) in which no significant correlations were obtained among temporal variables with $T_{1}$. According to our findings, increasing

Table 2. Descriptive statistics of the variables $(\mathrm{N}=30)$

\begin{tabular}{cll}
\hline Variables & Mean \pm SD \\
\hline$T_{1}(s)$ & $0.027 \pm 0.016$ \\
\hline$T_{2}(s)$ & $0.083 \pm 0.034$ \\
\hline$F_{1}(B W)$ & $1.801 \pm 0.49$ \\
\hline$F_{2}(B W)$ & $3.439 \pm 0.835$ \\
\hline$T_{f}(s)$ & $0.277 \pm 0.096$ \\
$T_{p}(s)$ & $0.055 \pm 0.023$ \\
$M_{1}(c m)$ & $45.533 \pm 4.684$ \\
$F_{2} / F_{1}$ & $1.999 \pm 0.534$ \\
$T_{1} / T_{f}$ & $0.108 \pm 0.067$ \\
$T_{2} / T_{f}$ & $0.315 \pm 0.107$ \\
\hline
\end{tabular}


Table 3. The Pearson coefficient sig(2-tailed) between selected kinetics and temporal variables of landing from a block jump in junior elite volleyball players $(\mathrm{N}=30)$

\begin{tabular}{|c|c|c|c|c|c|c|c|c|c|c|c|}
\hline Pears & Coefficient & $T_{1}$ & $T_{2}$ & $F_{1}$ & $F_{2}$ & $T_{p}$ & $T_{f}$ & $F_{2} / F_{1}$ & $T_{1} / T_{f}$ & $T_{2} / T_{f}$ & $M_{1}$ \\
\hline \multirow{2}{*}{$\mathrm{T}_{1}$} & \multirow{2}{*}{$\begin{array}{l}\text { Pearson } \\
\text { Coefficient }\end{array}$} & 1 & $0.793^{*}$ & 0.138 & -0.435 & $0.453^{\dagger}$ & 0.443 & $-0.577^{*}$ & $0.558^{\dagger}$ & 0.403 & -0.080 \\
\hline & & & 0.000 & 0.561 & 0.056 & 0.045 & 0.050 & 0.008 & 0.011 & 0.078 & 0.736 \\
\hline \multirow{2}{*}{$\mathrm{T}_{2}$} & \multirow{2}{*}{$\begin{array}{l}\text { Pearson } \\
\text { Coefficient }\end{array}$} & $0.793^{*}$ & 1 & -0.171 & $-0.629 *$ & $0.902 *$ & $0.583^{*}$ & -0.275 & 0.192 & 0.362 & -0.352 \\
\hline & & 0.00 & & 0.472 & 0.003 & 0.000 & 0.007 & 0.240 & 0.418 & 0.116 & 0.128 \\
\hline \multirow{2}{*}{$\mathrm{F}_{1}$} & \multirow{2}{*}{$\begin{array}{c}\text { Pearson } \\
\text { Coefficient }\end{array}$} & 0.138 & -0.171 & 1 & $0.532+$ & -0.347 & -0.213 & $-0.645^{*}$ & 0.164 & -0.041 & $0.752 *$ \\
\hline & & 0.561 & 0.472 & & 0.016 & 0.134 & 0.366 & .002 & 0.490 & 0.862 & 0.00 \\
\hline \multirow{2}{*}{$\mathrm{F}_{2}$} & \multirow{2}{*}{$\begin{array}{l}\text { Pearson } \\
\text { Coefficient }\end{array}$} & -0.435 & $-0.629 *$ & $0.532+$ & 1 & $-0.612^{*}$ & -0.316 & 0.241 & -0.294 & $-0.472+$ & $0.565^{*}$ \\
\hline & & 0.056 & 0.003 & 0.016 & & 0.004 & 0.175 & 0.306 & 0.208 & 0.036 & 0.009 \\
\hline \multirow{2}{*}{$T_{p}$} & \multirow{2}{*}{$\begin{array}{c}\text { Pearson } \\
\text { Coefficient }\end{array}$} & $0.453^{\dagger}$ & $0.902 *$ & -0.347 & $-0.612^{*}$ & 1 & $0.540^{\dagger}$ & 0.005 & -0.114 & 0.246 & $-0.459 \dagger$ \\
\hline & & 0.045 & 0.000 & 0.134 & 0.004 & & 0.014 & 0.983 & 0.633 & 0.297 & 0.042 \\
\hline \multirow{2}{*}{$T_{f}$} & \multirow{2}{*}{$\begin{array}{l}\text { Pearson } \\
\text { Coefficient }\end{array}$} & 0.443 & $0.583^{*}$ & -0.213 & -0.316 & $0.540^{+}$ & 1 & -0.061 & -0.384 & $-0.464{ }^{\dagger}$ & -0.227 \\
\hline & & 0.050 & 0.007 & 0.366 & 0.175 & 0.014 & & 0.799 & 0.094 & 0.039 & 0.336 \\
\hline \multirow{2}{*}{$F_{2} / F_{1}$} & \multirow{2}{*}{$\begin{array}{c}\text { Pearson } \\
\text { Coefficient }\end{array}$} & $-0.577^{*}$ & -0.275 & $-0.645^{*}$ & 0.241 & 0.005 & -0.061 & 1 & $-0.492+$ & -0.287 & -0.389 \\
\hline & & 0.008 & 0.240 & 0.002 & 0.306 & 0.983 & 0.799 & & 0.028 & 0.220 & 0.090 \\
\hline \multirow{2}{*}{$T_{1} / T_{f}$} & \multirow{2}{*}{$\begin{array}{l}\text { Pearson } \\
\text { Coefficient }\end{array}$} & $0.558^{+}$ & 0.192 & 0.164 & -0.294 & -0.114 & -0.384 & $-0.492+$ & 1 & $0.833^{*}$ & 0.008 \\
\hline & & 0.011 & 0.418 & 0.490 & 0.208 & 0.633 & 0.094 & 0.028 & & 0.000 & 0.972 \\
\hline \multirow{2}{*}{$T_{2} / T_{f}$} & \multirow{2}{*}{$\begin{array}{l}\text { Pearson } \\
\text { Coefficient }\end{array}$} & 0.403 & 0.362 & -0.041 & $-0.472+$ & 0.246 & $-0.464 \dagger$ & -0.287 & $0.833^{*}$ & 1 & -0.207 \\
\hline & & 0.078 & 0.116 & 0.862 & 0.036 & 0.297 & 0.039 & 0.220 & 0.000 & & 0.382 \\
\hline \multirow{2}{*}{$M_{\jmath}$} & \multirow{2}{*}{$\begin{array}{l}\text { Pearson } \\
\text { Coefficient }\end{array}$} & -0.080 & -0.352 & $0.752^{*}$ & $0.565^{*}$ & $-0.459 *$ & -0.227 & -0.389 & 0.008 & -0.207 & 1 \\
\hline & & 0.736 & 0.128 & 0.000 & 0.009 & 0.042 & 0.336 & 0.090 & 0.972 & 0.382 & \\
\hline
\end{tabular}

† Correlation is significant at the 0.05 level (2-tailed); * Correlation is significant at the 0.01 level (2-tailed).

PHYSICAL TREA $\mid$ MENTS

$\mathrm{T}_{1}$ leads to an increase in $\mathrm{T}_{2}, \mathrm{~T}_{\mathrm{p}}$, and $\mathrm{T}_{\mathrm{f}}$. It is evident that a soft landing needs a longer period, and temporal variables will be higher than a hard landing. Abian et al. suggest that $T_{1}$ is not as important as $T_{2}$ or $T_{p}$ in shock absorption [34].

As an essential factor that is a determinant of injury, increasing $\mathrm{T}_{2}$ increases $\mathrm{T}_{\mathrm{f}}$ and $\mathrm{T}_{\mathrm{p}}$ and thus better shock absorption. Inconsistent with other studies that implied a negative relationship between $\mathrm{T}_{2}$ and $\mathrm{T}_{1}$, our positive relationship is not suitable for volleyball players as they ought to be ready for the next skill, so minimizing the landing time is of great importance. Increasing landing time concerning an increase in $\mathrm{T}_{2}$ could be counterproductive according to the volleyball goals.

Table 3 indicates significant correlations between the first and second peaks. No other study reported contrary to our finding. Low values of $F_{1}$ and $F_{2}$ indicate that subjects were all adopted to soft landing style. Moreover, it must be considered that impact forces are dependent on each other.

Negative significant correlations between $T_{2}$ and $T_{p}$ with $\mathrm{F}_{2}$ are consistent with Abien et al. and Ortega et al. results $[15,34]$. It suggests that $\mathrm{F}_{2}$ was delayed as its value decreased. As mentioned earlier, to decrease $\mathrm{F}_{2}$, 
total landing time should be increased, and the COM must be further displaced.

Significant correlations between MJ and peak forces $\left(\mathrm{F}_{1}, \mathrm{~F}_{2}\right)$ seem logical. As the jump height increase, the impact forces will increase. Thus to decrease forces, the landing technique must be noticed. A significant negative correlation between $\mathrm{MJ}$ and $\mathrm{T}_{\mathrm{p}}$ is perhaps due to controlling and achieving the balance of the body, especially for volleyball players that balance is considered a vital component not only for performance enhancement but also for decreasing injuries.

Results show lower values for $\mathrm{F}_{1}$ and $\mathrm{F}_{2}$, which state that volleyball players are well known and skilled in the landing technique. Volleyball players are adopted to landing style. Decreasing excessive forces caused by landing from a blocking technique in volleyball will be applicable by altering kinetic and temporal variables. Investigating the relationship between kinetic and temporal variables, especially two peak forces of the force-time curve, is of great importance and logically a relevant solution for injury prevention. It should be noticed that volleyball is a dynamic sport, and isolating a technique is not very realistic. So we recommend that further investigations consider series of jumping or combined techniques such as consecutive block jumping. Moreover, the role of the upper extremity should be mentioned in shock absorption and reducing injuries causing by landing from a block jump.

\section{Conclusion}

Because of the high rate of lower extremity injuries causing by landing from a block in volleyball, players should be aware of appropriate techniques and important parameters affecting harmful forces. It is suggested that the second peak of landing is responsible for the majority of volleyball injuries. Significant correlations between MJ height and temporal and kinetics variables of landing suggest that optimum timing in landing would lead to optimum shock absorption. As volleyball players are good jumpers, great stress would be placed on their lower extremities when landing. Increasing the time of the second peak $\left(\mathrm{T}_{2}\right)$ will decrease impact force $\left(\mathrm{F}_{2}\right)$, although it is not appropriate for volleyball goals. The results of our study are applicable for coaches and volleyball players in instructing suitable landing techniques, especially for beginners, and promoting performance regarding injury prevention.

\section{Ethical Considerations}

\section{Compliance with ethical guidelines}

The participants were informed about the purpose of the research and its implementation stages. They were also assured about the confidentiality of their information and were free to leave the study whenever they wished, and if desired, the research results would be available to them.

\section{Funding}

This research received no specific grant from any funding agency in the public, commercial, or non-profit sectors.

\section{Authors' contributions}

All authors equally contributed in preparing this article.

\section{Conflict of interest}

The authors declared no conflict of interest.

\section{Acknowledgments}

The authors would like to express their best appreciation to the Junior National Volleyball Players and the staff of Biomechanics Lab. in the National Olympic Academy.

\section{References}

[1] Fatahi A, Sadeghi H, Ameli M. Relationship between injury types and prevalence with some anthropometric properties of male elite volleyball players of Iran. World Applied Sciences Journal. 2011; 15(5):667-72. http://www. idosi.org/wasj/wasj15(5)11/9.pdf

[2] Beneka A, Malliou P, Gioftsidou A, Tsigganos G, Zetou H, Godolias G. Injury incidence rate, severity and diagnosis in male volleyball players. Sport Sciences for Health. 2009; 5:93-9. [DOI:10.1007/s11332-009-0083-9]

[3] Salci Y, Kentel BB, Heycan C, Akin S, Korkusuz F. Comparison of landing maneuvers between male and female college volleyball players. Clinical Biomechanics. 2004; 19(6):622-8. [DOI:10.1016/j.clinbiomech.2004.03.006] [PMID] 
[4] Fuchs RK, Bauer JJ, Snow CM. Jumping improves hip and lumbar spine bone mass in prepubescent children: A randomized controlled trial. Journal of Bone and Mineral Research. 2001; 16(1):148-56. [DOI:10.1359/ jbmr.2001.16.1.148] [PMID]

[5] Fuchs RK, Cusimano B, Snow CM. Box jumping: A bonebuilding exercise for elementary school children. Journal of Physical Education, Recreation \& Dance. 2002; 73(2):225. [DOI:10.1080/07303084.2002.10607749]

[6] Yeow CH, Rubab SK, Lee PV, Goh JC. Inhibition of anterior tibial translation or axial tibial rotation prevents anterior cruciate ligament failure during impact compression. The American Journal of Sports Medicine. 2009; 37(4):81321. [DOI:10.1177/0363546508328418] [PMID]

[7] Podraza JT, White SC. Effect of knee flexion angle on ground reaction forces, knee moments and muscle co-contraction during an impact-like deceleration landing: Implications for the non-contact mechanism of ACL injury. The Knee. 2010; 17(4):291-5. [DOI:10.1016/j.knee.2010.02.013] [PMID]

[8] Fong DT, Hong Y, Chan LK, Yung PS, Chan KM. A systematic review on ankle injury and sprain in sports. Sports Medicine. 2007; 37(1):73-94. [DOI:10.2165/00007256-
[D 200737010-00006] [PMID]

[9] McNair PJ, Prapavessis H, Callender K. Decreasing landing forces: Effect of instruction. British Journal of Sports Medicine. 2000; 34(4):293-6. [DOI:10.1136/bjsm.34.4.293] [PMID] [PMCID]

[10] Lian O, Engebretsen L, Ovrebø RV, Bahr R. Characteristics of the leg extensors in male volleyball players with jumper's knee. The American Journal of Sports Medicine. 1996; 24(3):380-5. [DOI:10.1177/036354659602400322] [PMID]

[11] Tillman MD, Hass CJ, Brunt D, Bennett GR. Jumping and landing techniques in elite women's volleyball. Journal of Sports Science \& Medicine. 2004; 3(1):30-6. [PMID]

[12] Bressel E, Cronin J. The landing phase of a jump strategies to minimize injuries. Journal of Physical Education, Recreation \& Dance. 2005; 76(2):30-5. [DOI:10.1080/07303 084.2005.10607332]

[13] Chockley C. Ground reaction force comparison between jumps landing on the full foot and jumps landing en pointe in ballet dancers. Journal of Dance Medicine \& Science: Official Publication of the International Association for Dance Medicine \& Science. 2008; 12(1):5-8. [PMID]

[14] Carcia CR, Kivlan BR, Scibek JS. Time to peak force is related to frontal plane landing kinematics in female athletes. Physical Therapy in Sport. 2012; 13(2):73-9. [DOI:10.1016/j.ptsp.2011.06.003] [PMID]

[15] Ortega DR, Rodríguez Bíes EC, Berral de la Rosa FJ. Analysis of the vertical ground reaction forces and temporal factors in the landing phase of a countermovement jump. Journal of Sports Science \& Medicine. 2010; 9(2):282-7. [PMID]

[16] Devita P, Skelly WA. Effect of landing stiffness on joint kinetics and energetics in the lower extremity. Medicine and Science in Sports and Exercise. 1992; 24(1):108-15 [DOI:10.1249/00005768-199201000-00018] [PMID]

[17] Chappell JD, Herman DC, Knight BS, Kirkendall DT, Garrett WE, Yu B. Effect of fatigue on knee kinet- ics and kinematics in stop-jump tasks. The American Journal of Sports Medicine. 2005; 33(7):1022-9. [DOI:10.1177/0363546504273047] [PMID]

[18] Decker MJ, Torry MR, Wyland DJ, Sterett WI, Richard Steadman J. Gender differences in lower extremity kinematics, kinetics and energy absorption during landing. Clinical Biomechanics. 2003; 18(7):662-9. [PMID] [DOI:10.1016/S0268-0033(03)00090-1]

[19] Reiser RF, Rocheford EC, Armstrong CJ. Building a better understanding of basic mechanical principles through analysis of the vertical jump. Strength and Conditioning Journal. 2006; 28(4):70-80. [DOI:10.1519/00126548200608000-00012]

[20] Jacobs CA, Uhl TL, Mattacola CG, Shapiro R, Rayens WS. Hip abductor function and lower extremity landing kinematics: Sex differences. Journal of Athletic Training. 2007; 42(1):76-83. [PMID]

[21] Lindenberg KM, Carcia CR, Phelps AL, Martin RL, Burrows AM. The influence of heel height on sagittal plane knee kinematics during landing tasks in recreationally active and athletic collegiate females. International Journal of Sports Physical Therapy. 2011; 6(3):186-98. [PMID] [PMcID]

[22] Chappell JD, Creighton RA, Giuliani C, Yu B, Garrett WE. Kinematics and electromyography of landing preparation in vertical stop-jump: Risks for noncontact anterior cruciate ligament injury. The American Journal of Sports Medicine. 2007; 35(2):235-41. [DOI:10.1177/0363546506294077] [PMID]

[23] Zhang SN, Bates BT, Dufek JS. Contributions of lower extremity joints to energy dissipation during landings. Medicine and Science in Sports and Exercise. 2000; 32(4):812-9. [DOI:10.1097/00005768-200004000-00014] [PMID]

[24] Self BP, Paine D. Ankle biomechanics during four landing techniques. Medicine and Science in Sports and Exercise. 2001; 33(8):1338-44. [DOI:10.1097/00005768-20010800000015] [PMID]

[25] McNitt-Gray JL. Kinetics of the lower extremities during drop landing from three heights. Journal of Biomechanics. 1993; 26(9):1037-46. [DOI:10.1016/S0021-9290(05)80003-X] [PMID]

[26] Yeow CH, Lee PV, Goh JC. Regression relationships of landing height with ground reaction forces, knee flexion angles, angular velocities and joint powers during doubleleg landing. The Knee. 2009; 16(5):381-6. [DOI:10.1016/j. knee.2009.02.002] [PMID]

[27] Hughes G, Watkins J, Owen N. Differences between the sexes in knee kinetics during landing from volleyball block jumps. European Journal of Sport Science. 2010; 10(1):1-11. [DOI:10.1080/17461390903108117]

[28] Yu B, Lin CF, Garrett WE. Lower extremity biomechanics during the landing of a stop-jump task. Clinical Biomechanics. 2006; 21(3):297-305. [DOI:10.1016/j.clinbiomech.2005.11.003] [PMID]

[29] Zahradnik D, Jandacka D, Uchytil J, Farana R, Hamill J. Lower extremity mechanics during landing after a volleyball block as a risk factor for anterior cruciate ligament injury. Physical Therapy in Sport. 2015; 16(1):53-8. [DOI:10.1016/j.ptsp.2014.04.003] [PMID]

[30] Yeow CH, Lee PV, Goh JC. Non-linear flexion relationships of the knee with the hip and ankle, and their rela- 
tive postures during landing. The Knee. 2011; 18(5):323-8. [DOI:10.1016/j.knee.2010.06.006] [PMID]

[31] Marquez WQ, Masumura M, Ae M. The effects of jumping distance on the landing mechanics after a volleyball spike. Sports Biomechanics. 2009; 8(2):154-66. [DOI:10.1080/14763140902994435] [PMID]

[32] Ozgüven HN, Berme N. An experimental and analytical study of impact forces during human jumping. Journal of Biomechanics. 1988; 21(12):1061-6. [DOI:10.1016/00219290(88)90252-7] [PMID]

[33] Jidovtseff B, Quievre J, Harris NK, Cronin JB. Influence of jumping strategy on kinetic and kinematic variables. The Journal of Sports Medicine and Physical Fitness. 2014; 54(2):129-38. [PMID]

[34] Abián J, Alegre LM, Lara AJ, Rubio JA, Aguado X. Landing differences between men and women in a maximal vertical jump aptitude test. The Journal of Sports Medicine and Physical Fitness. 2008; 48(3):305-10. [PMID]

[35] Pappas E, Carpes FP. Lower extremity kinematic asymmetry in male and female athletes performing jump-landing tasks. Journal of Science and Medicine in Sport. 2012; 15(1):87-92. [DOI:10.1016/j.jsams.2011.07.008] [PMID]

[36] Lees A. Methods of impact absorption when landing from a jump. Engineering in Medicine. 1981; 10(4):207-11. [DOI:10.1243/EMED_JOUR_1981_010_055_02] 
This Page Intentionally Left Blank 